\title{
Prospective Isolation of Mesenchymal Stem Cells from Multiple Mammalian Species Using Cross-Reacting Anti-Human Monoclonal Antibodies
}

\author{
Henk Rozemuller, ${ }^{1,{ }^{*}}$ Henk-Jan Prins, ${ }^{1,{ }^{*}}$ Benno Naaijkens, ${ }^{1}$ Jojet Staal, \\ Hans-Jörg Bühring, ${ }^{2}$ and Anton C. Martens
}

\begin{abstract}
Mesenchymal stem cells (MSCs) of human and nonhuman mammalian species are often studied for various applications in regenerative medicine research. These MSCs can be derived from human bone marrow (BM) and identified by their ability to form fibroblast-like colony forming units that develop into stromal like cells when expanded in culture. These cells are characterized by their spindle-shaped morphology, their characteristic phenotype $\left(\mathrm{CD}_{3} 3^{+}, \mathrm{CD} 90^{+}, \mathrm{CD} 105^{+}, \mathrm{CD} 45^{-}\right.$, and $\left.\mathrm{CD} 34^{-}\right)$, and their ability to differentiate into cells of the osteogenic, adipogenic, and chondrogenic lineages. However, the identification and purification of MSCs from nonhuman mammalian species is hampered by the lack of suitable monoclonal antibodies $(\mathrm{mAb})$. In this report, primary BM and cultured BM-derived MSCs of human and monkey, goat, sheep, dog, and pig were screened for cross-reactivity using a panel of $43 \mathrm{mAb}$, of which 22 react with either human $\mathrm{BM}$ mononuclear cells or cultured human MSCs. We found $7 \mathrm{mAb}$ with specificity for CD271, MSCA-1 (W8B2 antigen), W4A5, CD56, W3C4 (CD349), W5C4, and 58B1, which showed interspecies cross-reactivity. These mAb proved to be useful for prospective sorting of MSCs from the BM of the 6 mammalian species studied as well as for the characterization of their cultured offspring. Flow sorting with the cross-reacting mAb resulted in up to 2400 -fold enrichment of the clonogenic cell fraction (fibroblast-like colony forming units). This study provides an important contribution for the comparative prospective isolation of primary BM-MSCs and the characterization of cultured MSCs from multiple mammalian species for preclinical research.
\end{abstract}

\section{Introduction}

$\mathrm{M}$ ESENCHYMAL STEM/STROMAL CELls (MSCs) are nonhematopoietic cells that can be isolated from the adherent cell fraction from the bone marrow (BM). They have an extensive proliferation capacity and can produce offspring that can differentiate into osteoblasts, adipocytes, tenocytes, neurons, myoblasts, and stromal fibroblasts [1-3]. These characteristics position the MSCs as a central player in tissue repair and hold promise for the development of new therapeutics for application in regenerative medicine [4]. Cultures of isolated cells give rise to clonal outgrowth of initially plastic-adherent cells with a spindle-shaped morphology, defined as colony forming unit-fibroblast (CFU-F), that are multipotent in their differentiation capacity and are considered as a measure for clonogenic MSCs. The typical immunophenotype of human cultured MSCs includes ex- pression of CD73 (ecto-5'-nucleotidase, SH3, SH4), CD90 (Thy-1), and CD105 (endoglin, SH2) and the lack of hematopoietic markers [5].

Preclinical animal models are increasingly used to develop new strategies for treatment of human diseases into clinical practice and for testing of therapeutics based on MSCs or MSC-derived products. In orthopedic research, MSCs from goat [6-11], dog [12-15], sheep [16-19], and pig [20,21] are studied with the aim to correct defects of cartilage and bone. In cardiac research MSCs from dog [22-24], pig [25,26], and sheep $[27,28]$ are studied for heart valve reconstruction and for cellular therapy to treat myocardial infarctions. MSCs from rhesus monkey are investigated to treat neurological disorders [29-32]. The characterization of animal MSCs is inevitably restricted to morphology and in vitro differentiation capacity. Although the panel of monoclonal antibodies $(\mathrm{mAb})$ for immunophenotyping or isolation of human

\footnotetext{
${ }^{1}$ Department of Immunology, University Medical Center Utrecht, Utrecht, The Netherlands.

${ }^{2}$ Divisions of Hematology, Oncology, Immunology, and Rheumatology, Department of Internal Medicine II, University of Tübingen, Tübingen, Germany.

*These two authors contributed equally to this work.
} 
culture-expanded MSCs from BM or other sources is rapidly expanding, such $\mathrm{mAb}$ are currently not available for a variety of animal species that are increasingly used in regenerative medicine research.

Several $\mathrm{mAb}$ have been described that bind to a small subfraction of human BM cells or to culture expanded MSCs. These include Stro-1 [33], CD271 (low-affinity nerve growth factor receptor) [34], SSEA-4 [35], CD146 [36], CD49a [37], CD105 [38,39], GD2 [40], and CD140b [41] and can be used to enrich for the CFU-F cell fraction. The CFU-F is considered to be the precursor or stem cell that resides in the BM (primary MSCs) from which culture-expanded MSCs originate. CD271 is particularly interesting because all CFU-F in human BM reside in the $\mathrm{CD} 271^{+}$cell fraction [34], although only a minority of these cells have colony-forming ability. This indicates that additional specific $\mathrm{mAb}$ are required to obtain a pure clonogenic cell fraction from BM with a 100\% plating efficiency. Recently, we described a panel of mAb that reacted with a subfraction of the CD271 ${ }^{+}$cells in fresh human $\mathrm{BM}$ and/or BM-derived cultured MSCs $[42,43]$.

We considered that this panel of $\mathrm{mAb}$ interesting to test for cross-reactivity with MSCs from other mammalian species that are frequently used in regenerative medicine research. Here we report on $7 \mathrm{mAb}$ that showed cross-reactivity with primary MSCs in BM and with cultured MSCs from human as well as the other species that we investigated. Using flow sorting, we could define specific $\mathrm{mAb}$ combinations for prospective isolation of primary MSCs from BM. The experiments yielded high enrichment factors for the CFU-F fraction in the BM of all species. These results may have impact on regenerative-medicine-oriented preclinical animal model research or for the development of MSC-based therapeutic applications in the veterinary practice.

\section{Materials and Methods}

\section{Collection of BM}

Human BM was harvested by aspiration from the iliac crest from normal individuals during standard hip replacement surgery after written informed consent. Animal BM was harvested from the iliac crest (monkey, goat, and dog) or from the sternum (pig and sheep). The animals were housed in the Central Animal Facility of the University of Utrecht or in the Veterinary Faculty (dog, pig, goat, and sheep), the Universities of Amsterdam and Nijmegen (goat), or the University of Rotterdam (rhesus macaque). All animal handling was conducted according to Institutional Guidelines after acquiring permission from the local Ethics Committee for Animal Experiments and in accordance with current Dutch laws on animal experiments.

\section{Cell isolation and culturing of MSCs}

Mononuclear cells (MNCs) were isolated from human BM and animal BM aspirates by density gradient centrifugation (Ficoll $1.077 \mathrm{~g} / \mathrm{cm}^{3}$ ) and plated in noncoated $25 \mathrm{~cm}^{2}, 75 \mathrm{~cm}^{2}$ or $175 \mathrm{~cm}^{2}$ polystyrene culture flasks (Falcon-Becton Dickinson Biosciences) at a density of $160,000-250,000 \mathrm{MNCs} / \mathrm{cm}^{2}$. Human MNCs were seeded on $\alpha$-minimum essential medium (Life Technologies) supplemented with $5 \%(\mathrm{v} / \mathrm{v})$ human platelet lysate (Bloodbank Sanquin), $100 \mathrm{U} / \mathrm{mL}$ penicillin (Life Technologies), $100 \mu \mathrm{g} / \mathrm{mL}$ streptomycin (Life Technol- ogies), and 10 units/mL heparin (LEO Pharma) as previously described [44]. Cells from goat, sheep, pig, and dog were cultured in

$\alpha$-minimum essential medium, penicillin, and streptomycin, and supplemented with $15 \%$ heat-inactivated fetal bovine serum (FBS; Cambrex); monkey cell cultures were supplemented with $10 \%$ FBS (Cambrex). Cultures were maintained at $37^{\circ} \mathrm{C}$ at $5 \% \mathrm{CO}_{2}$ in a humid atmosphere. The medium was changed twice a week and the cells were harvested and passaged at near confluence (90\%). The MSCs of all species were harvested by trypsinization. MSCs were washed twice with phosphate-buffered saline (UMC Pharmacy) containing $2 \mathrm{mM}$ ethylenediaminetetraacetic acid and then incubated with trypsin-ethylenediaminetetraacetic acid (Lonza). The MSCs were collected by inactivating the trypsin with a medium containing 10\% FBS. After centrifugation (6 min, $1100 \mathrm{rpm}$ ) the cells were counted and used for passaging the cells, cryopreservation, or performing assays.

\section{CFU-F assay}

To determine the CFU-F frequency in BM or fluorescenceactivated cell sorter (FACS)-enriched MNCs, graded numbers of cells were seeded in triplo in Falcon 6-well plates or Falcon T-25 flasks with vented caps. The culture medium for each species was used as described. After 10 days the adherent cells were washed twice with phosphate-buffered saline and subsequently fixed with ice-cold methanol for $15 \mathrm{~min}$ at $4^{\circ} \mathrm{C}$. To observe the colonies, the cells were stained with Giemsa (Sigma-Aldrich) diluted 1:8 with $\mathrm{H}_{2} \mathrm{O}$ for $15 \mathrm{~min}$ at room temperature and washed twice with $\mathrm{H}_{2} \mathrm{O}$. CFU-F colonies containing at least 50 cells were scored using a Stereomicroscope (Zeiss).

\section{Antibodies, flow cytometric analysis, and sorting}

For the initial screening of cultured MSCs from the nonhuman species, we used a panel of $43 \mathrm{mAb}$ that contained the following commercially available mAb against human CD3, 13, 14, 19, 29, 31, 34, 44, 45, 49, 55, 71, 73, 90, 117, 146, HLA-ABC, HLA-DR, Sca-1 [45] (Becton Dickinson), CD105 (Ancell Corp.), CD235a (Dako), CD271 (Clone 20.4 against low-affinity nerve growth factor receptor-allophycocyanin; Miltenyi Biotec), ALP (clone B4-78-c; Hybridoma Bank), KDR (R\&D Systems), SSEA-4 (clone MC-813-70; Hybridoma Bank), W8B2 against human MSCs antigen-1 (MSCA-1/ W8B2-phycoerythrin (PE); Biolegend), W4A5 against MSCs, and neural progenitor cells (W4A5-PE; Biolegend). Additionally, we used a series of $\mathrm{mAb}$ that showed reactivity with the $\mathrm{CD} 271^{+}$subpopulation in human BM with putative MSCs specificity [46]. These mAb consisted of the clones W3C4 (CD349; frizzled-9), W5C4, and 39D5 (CD56 epitope expressed on MSCs but not on NK cells) or MY31 (anti-CD56 on MSCs and NK cells), W1C3, W6B3H10 (CD133), 24D2 (CD340), W5C5, 58B1, CH3A4A7A (CD344), 67D2 (CD164), W7C5 (CD109), 67A4 (CD324), 28D4 (CD140b), HEK-3D6, W3D5, and CUB1 (CD318) [41-43]. Binding of nonconjugated $\mathrm{mAb}$ was analyzed by staining with isotype-specific (IgG, IgG1, IgM, or IgG3) PE-conjugated goat anti-mouse antisera (Southern Biotechnology Associates, Inc.). Flow cytometric analysis was performed on a FACS Calibur, and cell sorting was performed on a FACSAria cytometer (Becton Dickinson Biosciences). About $1 \times 10^{6}$ primary BM cells or $1 \times 10^{4}$ cultured 

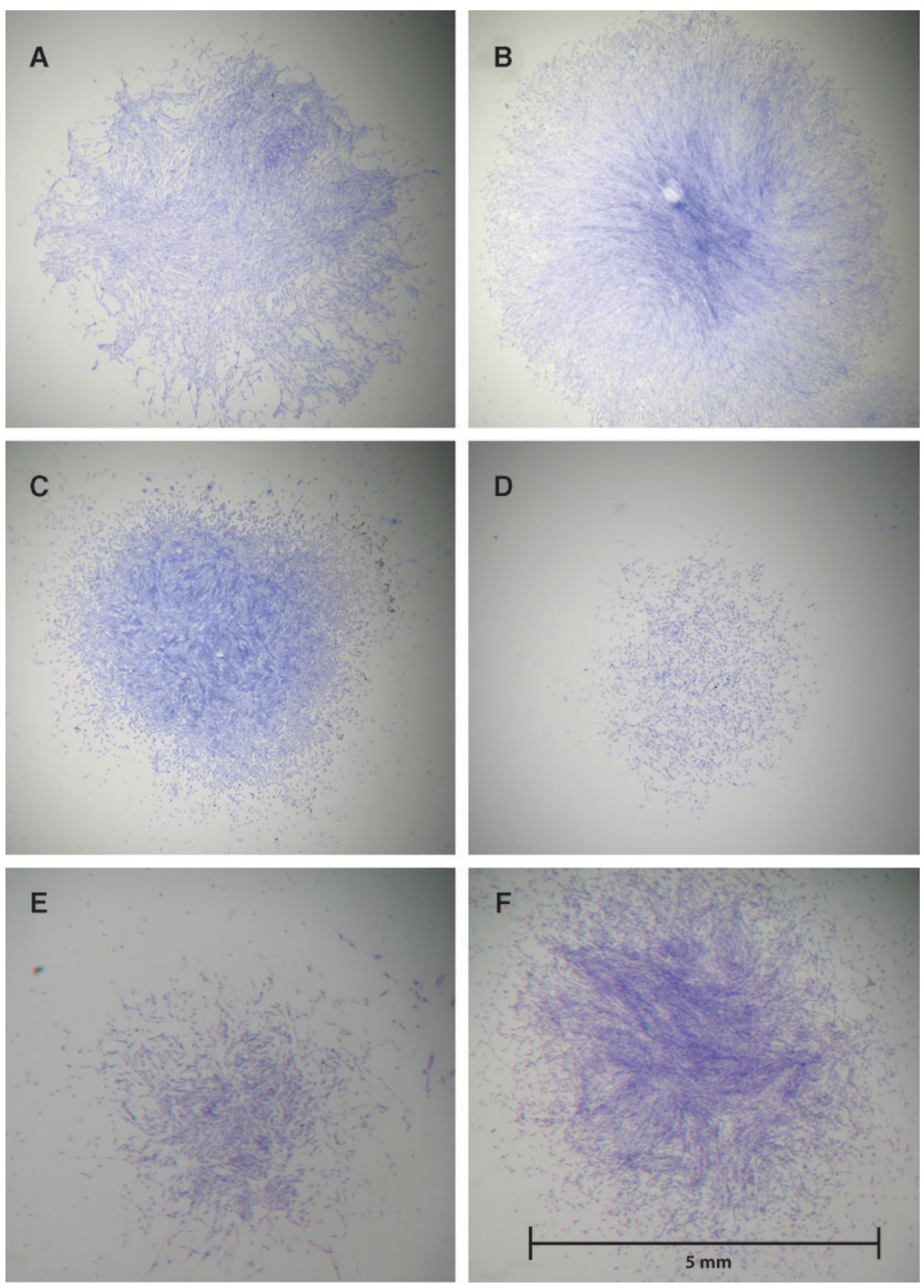

FIG. 1. Colony forming unit-fibroblast (CFU-F). Shown is a representative picture of one formed CFU-F colony for all the species tested: human (A), monkey (B), goat (C), dog (D), pig (E), and sheep (F). After 10 days of in vitro culture, colonies were fixed, and stained with Giemsa.

MSCs were acquired within the "live gate" based on light scatter properties.

\section{Experimental design}

In the initial screening we analyzed cultured MSCs at passage 2 or 3 for cross-reactivity using a panel of $43 \mathrm{mAb}$. Only 7 from $43 \mathrm{mAb}$ that reacted with more than $1 \%$ of the
MSCs of each of the species were considered interesting for further analysis of the binding characteristics of fresh BM and used for the flow sorting CFU-F enrichment experiments. We used 1 or $2 \times 10^{6} \mathrm{BM}$ cells for single labeling and 2 or $4 \times 10^{6}$ cells for double labeling and sorting experiments (depending on the yield after the Ficoll separation). At least 3 different individual BM samples from each species were processed. Sort regions were based on isotype controls or 
Table 1. Reactivity of Monoclonal Antibodies with Cultured Mesenchymal Stem Cells of Multiple Mammalian Species

\begin{tabular}{|c|c|c|c|c|c|c|}
\hline$m A b$ & Human & Monkey & Goat & $\operatorname{Dog}$ & Pig & Sheep \\
\hline CD73 & ++ & ++ & - & - & - & - \\
\hline CD90 & ++ & ++ & - & - & ++ & - \\
\hline CD105 & ++ & ++ & - & - & - & - \\
\hline CD146 & ++ & ++ & - & + & ++ & ++ \\
\hline CD271 & \pm & + & \pm & \pm & \pm & \pm \\
\hline SSEA-4 & ++ & ++ & + & - & - & - \\
\hline W8B2 (MSCA-1) & + & + & ++ & + & + & \pm \\
\hline W4A5 & + & + & + & + & + & + \\
\hline W3C4 (CD349) & ++ & ++ & \pm & \pm & + & + \\
\hline WIC3 & - & - & - & - & - & - \\
\hline W6B3H10 (CD133) & \pm & - & - & - & - & - \\
\hline 24D2 (CD340) & ++ & - & - & - & - & - \\
\hline W5C5 & + & - & - & - & + & - \\
\hline 58B1 & ++ & ++ & ++ & ++ & ++ & ++ \\
\hline 39D5 (CD56) & \pm & ++ & \pm & ++ & \pm & \pm \\
\hline CH3A4A7 (CD344) & - & - & - & - & - & - \\
\hline 67D2 (CD164) & ++ & - & - & - & - & - \\
\hline W7C5 (CD109) & ++ & - & - & - & - & - \\
\hline 67A4 (CD324) & \pm & - & - & - & - & - \\
\hline W5C4 & ++ & ++ & ++ & ++ & ++ & ++ \\
\hline 28D4 (CD140b) & ++ & - & - & - & - & - \\
\hline HEK-3D6 & ++ & - & - & - & - & - \\
\hline W3D5 & + & - & - & - & - & - \\
\hline CUBI (CD318) & ++ & - & - & - & - & - \\
\hline
\end{tabular}

$++:>50 \%$ of cells positive; + : between $50-5 \%$ positive; $\pm:>5<1 \%$ positive; - : below detection level.

Other $\mathrm{mAb}$ from our panel that were tested but did not show cross-reactivity between species include anti-human CD3, 13*,14, 19, 29*,31, $34,44^{*}, 45,49^{*}, 55^{*}, 71^{*}, 117,235 \mathrm{a}$, anti HLA-ABC* HLA-DR, Sca-1, ALP* and KDR.

${ }^{*} \mathrm{mAb}$ positive on human MSC.

$\mathrm{mAb}$, monoclonal antibodies.

binding of secondary antibody, and all cells obtained in the negative and positive (single or double) cell fractions were tested for the presence of clonogenic MSCs (CFU-F) by seeding one-third of the total sorted fraction per well in a 6-well plate in triplicate. CFU-F assays were performed as described. The enrichment of CFU-F after sorting was calculated by the following formula: CFU-F frequency in the mAb-based sorted fraction/CFU-F frequency in the total sorted MNCs fraction. The total sorted MNC fraction is defined as the cells appearing within the "live gate" based on light scatter properties and serves as a measure for CFU-F loss as a result of the sorting procedure.

\section{Results}

\section{Outgrowth of MSCs from BM}

The MNC fractions from BM aspirates of all species were analyzed for in vitro colony formation and for the production of BM-derived cultured MSCs. MNCs from all species contained adherent cells that developed into CFU-F that ultimately formed a confluent stromal cell layer. A colony is the result of the outgrowth of a single multipotent cell (defined as CFU-F), and the CFU-F frequency in BM is considered as a measure for the number of primary MSCs that are present. Figure 1 shows images taken from representative colonies for each of the species that we studied. The colonies consisted of cells with spindle-shape morphology, typical for cultured MSCs. The colony diameter was approximately $5 \mathrm{~mm}$ for most of the species, except for the dog (Fig. 1D) and the pig (Fig. 1E), of which the colonies contain fewer cells and the colonies are therefore somewhat smaller in size. We found a CFU-F frequency of 1 per 40,000 $\pm 20,000 \mathrm{MNC}$ for the species analyzed.

\section{Immunophenotyping of cultured MSCs from different species}

Cultured MSCs from all species were labeled with our standard panel of $43 \mathrm{mAb}$ for characterization of human MSCs and analyzed by flow cytometry to identify the mAb that show cross-reactivity between species. mAb recognizing CD73, CD90, CD105, CD146, and SSEA-4 showed crossreactivity between human and monkey MSCs but not with (all) the other species tested (Table 1). CD271, which is considered as one of the specific markers for human MSCs [34], showed binding to a subpopulation of cultured MSCs for all species studied (Fig. 2; Table 1) although the percentage of positive cells as well as the level of CD271 expression varied. Figure 2 and Table 1 show the characteristics of the other cross-reacting mAb. Whereas the mAb 58B1 and W5C4 showed binding to $100 \%$ of the cultured MSCs of all species, the mAb W8B2, W4A5, W3C4, and CD56 showed binding to MSC subpopulations ranging from 1 to $>50 \%$.

\section{Immunophenotyping and prospective sorting of clonogenic MSCs (CFU-F) from BM-MNCs}

The 7 identified mAb that cross-reacted to the cultured MSCs from all species were used to label BM-MNCs of all 


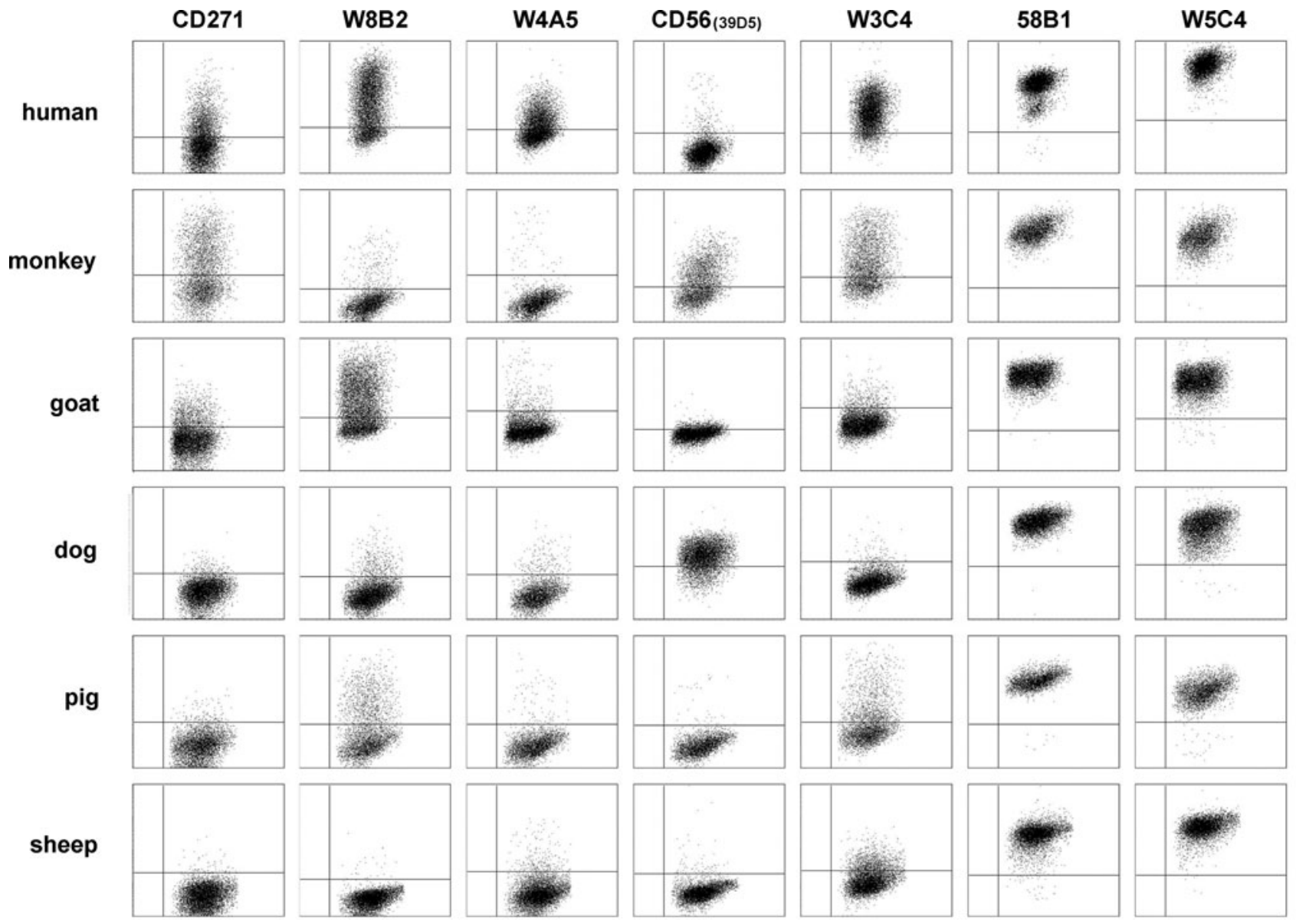

FIG. 2. Monoclonal antibodies (mAb) binding on cultured mesenchymal stem cells (MSCs). Fluorescence-activated cell sorter (FACS) dot plots showing cross-reactivity of the mAb CD271, W8B2, W4A5, CD56 (39D5), W3C4, 58B1, and W5C4 for culture-expanded human MSCs and MSCs of monkey, goat, dog, pig, and sheep. On the Y-axis the fluorescent intensity of allophycocyanin (APC) (CD271) or phycoerythrin (PE)-conjugated mAb is shown, and on the X-axis the forward scatter (FSC). The X-Y-axis quadrant setting (created by the crossing vertical and horizontal lines) was set based on isotype or secondary antibody controls.

species and analyzed by FACS. For all species a positive subfraction of the MNCs was present (Fig. 3; Table 2).

In the initial analysis, primary BM-MNCs were labeled with a single $\mathrm{mAb}$ and flow sorting was used to obtain the positive and the negative cell fraction for subsequent plating in a CFU-F assay and used to calculate the enrichment of the CFU-F. Single-antibody labeling and sorting revealed that the clonogenic MSCs from BM of human, monkey, goat, dog, sheep, and pig were enriched in the positive fraction although not to the same extent for each of the mAbs used (Table 3). Also, mAb that gave a high enrichment for one of the species did not always give high enrichment for other species. CFU-F grown from flow-sorted cells were identical in size and morphology as those from nonsorted cells, and when all recovered CFU-F are in the positive fraction, no cell growth or small colonies were observed in the negative fraction (data not shown). From all recovered CFU-F $>90 \%$ was restricted to the positive cell fraction for human and monkey for all mAb tested. For the other species, the mAb showed less specificity for the BM CFU-F compared with human, but was in general above $50 \%$ with a few exceptions (Table 4), although revealing enrichment (Table 3). The lowest recovery was achieved with W8B2 and CD56 for dog BM CFU-F of $16 \%$ and $14 \%$, but with a 8 - and 2 -fold enrichment, respectively. Although only $13 \%$ of the BM CFU-F for pig resides in the W8B2 positive fraction (Table 4), there was still a 25 -fold enrichment for the BM CFU-F compared with the total MNC fraction (Table 3).

To further enrich for the clonogenic MSCs fraction the mAb W8B2, W4A5 and anti-CD56 were combined with CD271 in a double labeling setup for flow sorting. Doublepositive cells were found in the BM of all species (Fig. 4). Although the frequency was relatively low, most of the CFU$\mathrm{F}(>90 \%)$ were recovered in the double-positive fraction for human and monkey for all mAb combinations (Table 4). Goat BM-MNCs showed a subpopulation in the CD271 ${ }^{+}$ W4A5 fraction (33\%). The labeling of pig and dog MNCs with W8B2 showed 2 subpopulations, CD271 ${ }^{+} \mathrm{W} 8 \mathrm{~B} 2^{+}$and $\mathrm{CD}_{271^{+} \text {W8B2 }}{ }^{-}$cells. For dog and pig $10 \%$ of CFU-F resided in the $\mathrm{CD}_{271^{+}} \mathrm{W}_{8 \mathrm{~B} 2}{ }^{+}$population, whereas $90 \%$ resided in the $\mathrm{CD} 271^{+} \mathrm{W} 8 \mathrm{~B} 2^{-}$population. Labeling with anti-CD56 revealed a $\mathrm{CD} 271^{+} \mathrm{CD} 56^{+}$and $\mathrm{CD} 271^{+} \mathrm{CD} 56^{-}$cell fraction in dog MNCs. The CFU-F resided for $22 \%$ in the CD271 ${ }^{+} \mathrm{CD} 56^{+}$ population and $78 \%$ in $\mathrm{CD} 271^{+} \mathrm{CD} 56^{-}$population. In pig 


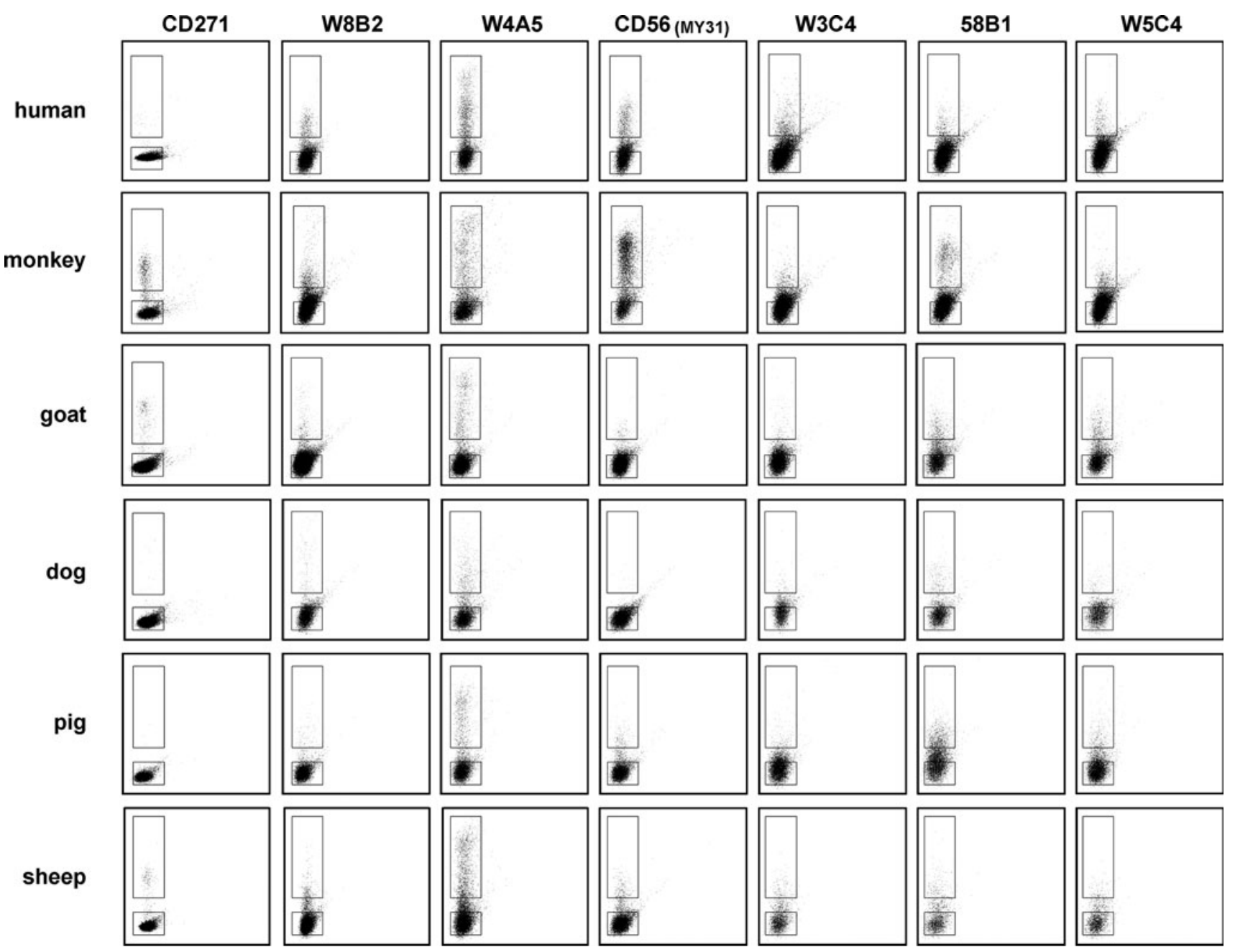

FIG. 3. Single mAb binding and FACS sorting of bone marrow (BM) mononuclear cells (MNCs) of multiple mammalian species. Flow cytometry dot plots after labeling of BM aspirate MNCs from the various species studied, that is, human, monkey, goat, dog, pig, and sheep, with the mAb CD271, W8B2, W4A5, CD56 (MY31), W3C4, 58B1, and W5C4 that showed cross-reactivity for culture-expanded MSCs of these species. On the Y-axis the fluorescent intensity of APC (CD271) or PEconjugated $\mathrm{mAb}$ is shown, and on the $\mathrm{X}$-axis the FL1 channel. The square boxes indicate the sort regions based on isotype controls or binding of secondary antibody. Both positive (upper region) and negative (lower region) cell fractions were tested for the presence of clonogenic MSCs (CFU-F).

Table 2. Binding of Selected Monoclonal Antibodies to Bone Marrow Mononuclear Cell Fraction

\begin{tabular}{|c|c|c|c|c|c|c|}
\hline$m A b$ & Human & Monkey & Goat & $\operatorname{Dog}$ & Pig & Sheep \\
\hline \multicolumn{7}{|l|}{ Single $\mathrm{mAb}$ labeling } \\
\hline CD271 & $0.5 \pm 0.3$ & $10.4 \pm 6.5$ & $1.0 \pm 0.7$ & $1.0 \pm 1.5$ & $0.3 \pm 0.6$ & $2.5 \pm 0.8$ \\
\hline W8B2 & $0.9 \pm 0.4$ & $9.4 \pm 4.9$ & $2.2 \pm 1.2$ & $5.5 \pm 4.2$ & $3.9 \pm 6.8$ & $19.2 \pm 15.4$ \\
\hline W4A5 & $5.5 \pm 3.4$ & $13.2 \pm 5.7$ & $8.5 \pm 3.5$ & $9.7 \pm 3.8$ & $7.8 \pm 6.8$ & $12.2 \pm 2.0$ \\
\hline CD56 (MY31) & $2.0 \pm 2.3$ & $31.4 \pm 17.2$ & $0.9 \pm 0.6$ & $0.6 \pm 0.2$ & $1.3 \pm 0.7$ & $0.8 \pm 0.1$ \\
\hline CD349 (W3C4) & $9.0 \pm 5.9$ & $4.6 \pm 2.7$ & $4.1 \pm 2.2$ & $3.9 \pm 1.3$ & $2.7 \pm 1.6$ & $5.8 \pm 3.0$ \\
\hline 58B1 & $5.0 \pm 0.7$ & $5.7 \pm 2.5$ & $4.5 \pm 3.9$ & $10.6 \pm 7.6$ & $31.5 \pm 25.3$ & $10.9 \pm 2.5$ \\
\hline W5C4 & $6.4 \pm 2.5$ & $4.3 \pm 1.4$ & $5.5 \pm 3.3$ & $6.3 \pm 6.6$ & $3.7 \pm 1.6$ & $7.3 \pm 1.2$ \\
\hline \multicolumn{7}{|l|}{ Double mAb labeling } \\
\hline CD271/W8B2 & $0.10 \pm 0.08$ & $3.80 \pm 3.56$ & $0.11 \pm 0.16$ & $2.21 \pm 0.31$ & $0.05 \pm 0.04$ & $0.60 \pm 0.87$ \\
\hline CD271/W4A5 & $0.14 \pm 0.18$ & $1.83 \pm 1.37$ & $0.21 \pm 0.01$ & $0.48 \pm 0.62$ & $0.04 \pm 0.03$ & $1.45 \pm 1.91$ \\
\hline CD271/CD56 (MY31) & $0.11 \pm 0.17$ & $9.07 \pm 5.30$ & $0.10 \pm 0.01$ & $0.18 \pm 0.26$ & $0.03 \pm 0.02$ & $0.10 \pm 0.00$ \\
\hline
\end{tabular}

The numbers are the mean percentage \pm standard deviation of positive cells stained with the indicated mAb in at least 3 different bone marrow mononuclear fractions. 
Table 3. Enrichment Factors for Colony Forming Unit-Fibroblast from the Bone Marrow Mononuclear Cell Fraction After Single or Double Monoclonal Antibody Labeling and Flow Sorting

\begin{tabular}{|c|c|c|c|c|c|c|}
\hline$m A b$ & Human & Monkey & Goat & $\operatorname{Dog}$ & Pig & Sheep \\
\hline \multicolumn{7}{|l|}{ Single $\mathrm{mAb}$ labeling } \\
\hline CD271 & $129 \pm 97$ & $13 \pm 8$ & $107 \pm 75$ & $88 \pm 95$ & $829 \pm 570$ & $49 \pm 29$ \\
\hline W8B2 & $86 \pm 91$ & $22 \pm 24$ & $43 \pm 55$ & $8 \pm 8$ & $25 \pm 19$ & $6 \pm 3$ \\
\hline W4A5 & $10 \pm 5$ & $9 \pm 2$ & $7 \pm 4$ & $14 \pm 2$ & $5 \pm 2$ & $9 \pm 4$ \\
\hline CD56 (MY31) & $33 \pm 30$ & $5 \pm 3$ & $113 \pm 133$ & $2 \pm 2$ & $52 \pm 19$ & $68 \pm 56$ \\
\hline CD349 (W3C4) & $18 \pm 6$ & $18 \pm 9$ & $6 \pm 9$ & $5 \pm 1$ & $14 \pm 1$ & $15 \pm 8$ \\
\hline $58 \mathrm{~B} 1$ & $47 \pm 23$ & $20 \pm 12$ & $54 \pm 10$ & $5 \pm 4$ & $2 \pm 1$ & $19 \pm 13$ \\
\hline W5C4 & $36 \pm 23$ & $19 \pm 2$ & $45 \pm 21$ & $41 \pm 20$ & $25 \pm 17$ & $23 \pm 15$ \\
\hline \multicolumn{7}{|l|}{ Double mAb labeling } \\
\hline CD271/W8B2 & $617 \pm 353$ & $47 \pm 22$ & $2392 \pm 1630$ & $53 \pm 59$ & $310 \pm 277$ & $314 \pm 281$ \\
\hline CD271/W4A5 & $431 \pm 214$ & $51 \pm 29$ & $512 \pm 402$ & $120 \pm 106$ & $880 \pm 476$ & $267 \pm 361$ \\
\hline CD271/CD56 (MY31) & $881 \pm 717$ & $23 \pm 17$ & $1504 \pm 1772$ & $17 \pm 19$ & $2374 \pm 1091$ & $512 \pm 326$ \\
\hline
\end{tabular}

The numbers represent the mean enrichment factors \pm standard deviation of at least 3 separate experiments. To calculate the enrichment factors for the CFU-F after single or double mAb labeling we divided the frequency of CFU-F in the mAb-based sorted fraction by the frequency of CFU-F in the total sorted MNC fraction.

BM-MNCs a subfraction of primary MSCs is located in the $\mathrm{CD} 271^{+} \mathrm{W} 4 \mathrm{~A} 5$ population (47\%). In Table 3 the average enrichment factors are shown. Although there was a broad range of enrichment factors, the frequency of clonogenic MSCs (CFU-F) was always increased.

\section{Discussion}

Here we report that from an initial panel of $43 \mathrm{mAb}$ with known specificity (positive or negative binding to human MSCs), $7 \mathrm{mAb}$, CD271, W3C4, CD56, W8B2, W4A5, 58B1, and $\mathrm{W} 5 \mathrm{C} 4$, react with the MSCs fraction in primary $\mathrm{BM}$ (CFU-F) and with cultured MSCs from human as well as from various mammalian species. These include the rhesus monkey, goat, sheep, pig, and dog. Some mAb have been described to bind to subpopulations of human BM containing the MSCs (CD146 [36], SSEA4 [35], and CD271 [34]. The markers that are the commonly used markers for defining human MSCs [5], CD73 (ecto-5'-nucleotidase, SH3, SH4), CD90 (Thy-1), and CD105 (endoglin, SH2), showed very limited cross-reactivity with MSCs from the other species. CD73 and CD105 showed cross-reactivity with monkey
MSCs and CD90 with monkey and pig MSCs, but were negative in all other species (Table 1).

The mAb CD271 (low-affinity nerve growth factor receptor) proved to be a most prominent marker in this study although its function on MSCs is unknown [34]. CD271 was expressed on MSCs of all species, and flow sorting of the positive fraction resulted in a significant enrichment of the CFU-F population in the BM. In a previous study we reported a strategy to identify new $\mathrm{mAb}$ that specifically react with the CFU-F fraction in human BM by searching for reactivity with the CD271 $1^{\text {bright }}$ fraction [42]. We observed that besides CD271, also W3C4, CD56, W8B2, W4A5, 58B1, and W5C 4 cross-react with a population containing CFU-F in the BM of all species studied (Table 4). This suggests that the structures recognized by these antibodies are relatively conserved. A few targets are identified. W3C4 binds to CD349 also known as frizzled-9, which is a transmembrane receptor activated by Wnt ligands [47]. It was shown that this $\mathrm{Ab}$ could be used for selective MSCs isolation from human placenta [41]. Recently, we showed that MSCA-1 is identical to tissue-nonspecific alkaline phosphatase, an ectoenzyme known to be expressed at high levels in liver, bone,

Table 4. Recovery of Mesenchymal Stem Cell Progenitors (Colony Forming Unit-Fibroblast) in the Different Bone Marrow Mononuclear Subfractions, Flow Sorted with Either One or a Combination of Monoclonal Antibodies

\begin{tabular}{|c|c|c|c|c|c|c|}
\hline$m A b$ & Human & Monkey & Goat & $\operatorname{Dog}$ & Pig & Sheep \\
\hline \multicolumn{7}{|l|}{ Single mAb labeling } \\
\hline CD271 & $100 \pm 0$ & $94 \pm 5$ & $100 \pm 0$ & $99 \pm 1$ & $98 \pm 5$ & $90 \pm 18$ \\
\hline W8B2 & $100 \pm 0$ & $100 \pm 0$ & $98 \pm 2$ & $16 \pm 21$ & $13 \pm 7$ & $84 \pm 14$ \\
\hline W4A5 & $93 \pm 7$ & $98 \pm 3$ & $67 \pm 16$ & $58 \pm 50$ & $74 \pm 27$ & $99 \pm 1$ \\
\hline CD56 (MY31) & $99 \pm 2$ & $97 \pm 4$ & $99 \pm 1$ & $14 \pm 16$ & $100 \pm 0$ & $98 \pm 2$ \\
\hline CD349 (W3C4) & $97 \pm 4$ & $99 \pm 2$ & $53 \pm 49$ & $92 \pm 10$ & $99 \pm 2$ & $99 \pm 1$ \\
\hline 58B1 & $100 \pm 0$ & $100 \pm 0$ & $100 \pm 0$ & $99 \pm 1$ & $100 \pm 0$ & $100 \pm 0$ \\
\hline W5C4 & $99 \pm 1$ & $100 \pm 0$ & $100 \pm 0$ & $100 \pm 0$ & $100 \pm 0$ & $100 \pm 0$ \\
\hline \multicolumn{7}{|l|}{ Double mAb labeling } \\
\hline CD271/W8B2 & $100 \pm 0$ & $94 \pm 5$ & $98 \pm 2$ & $10 \pm 17$ & $10 \pm 9$ & $84 \pm 14$ \\
\hline CD271/W4A5 & $93 \pm 7$ & $93 \pm 6$ & $67 \pm 16$ & $87 \pm 9$ & $53 \pm 18$ & $75 \pm 33$ \\
\hline CD271/CD56 (MY31) & $99 \pm 2$ & $93 \pm 4$ & $99 \pm 1$ & $22 \pm 13$ & $99 \pm 1$ & $96 \pm 0$ \\
\hline
\end{tabular}

The numbers are the mean percentage \pm standard deviation of at least 3 separate experiments. 


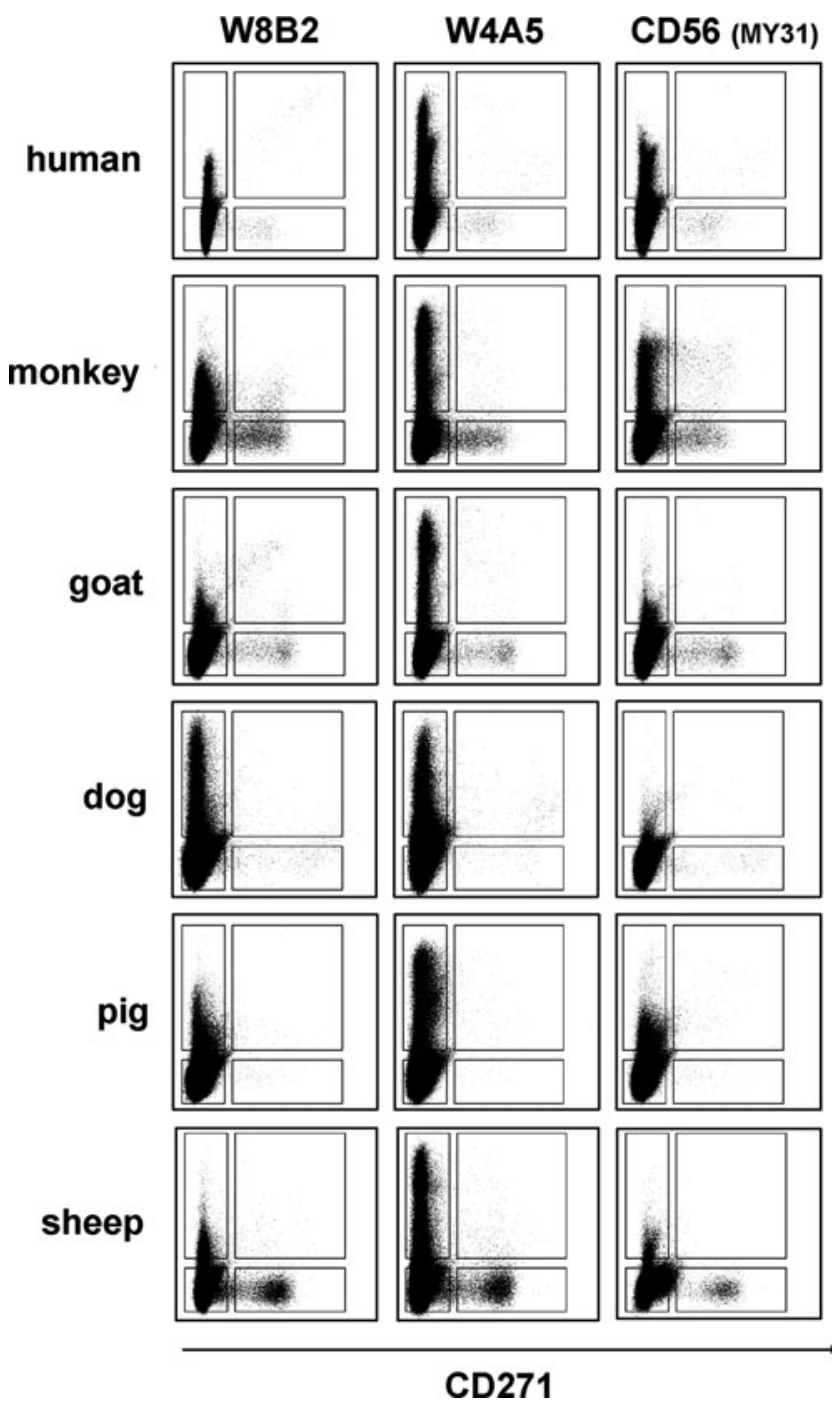

FIG. 4. Double mAb binding and FACS sorting of BMMNCs of multiple mammalian species. FACS dot plots after double labeling of $\mathrm{BM}$ aspirate MNCs from the various species studied, that is, human, monkey, goat, dog, pig, and sheep, with the mAb CD271 in combination with W8B2, W4A5, or CD56 (MY31), respectively. On the X-axis the fluorescent intensity of CD271-APC-conjugated $\mathrm{mAb}$ is shown, and on the $\mathrm{Y}$-axis the indicated PE-conjugated $\mathrm{mAb}$ is shown. The square boxes indicate the sort regions that are based on isotype controls or binding of secondary Ab. All 4 sorted fractions $(-/-,+/-,-/+$, and $+/+)$ were tested for the presence of clonogenic MSCs (CFU-F).

and kidney as well as in embryonic stem (ES) cells [48]. CD56 can be used to distinguish a subpopulation of adipogenic progenitors [43]. Primary MSCs already committed into a specific differentiation lineage can directly be isolated from the MNCs fraction using MSCA-1 (W8B2) and CD56 to demonstrate that only cells of the MSCA- $1^{+} \mathrm{CD} 56^{+}$fraction gave rise to effective induction of chondrocyte and pancreatic-like islet differentiation, and that adipocytes emerged only from MSCA-1 ${ }^{+} \mathrm{CD}^{-} 6^{-}$cells [43]. We observed no CFU-F in the CD271 ${ }^{+} \mathrm{CD} 56^{-}$cells; however, this might be related to the fact that we used an alternative $\mathrm{Ab}$ clone to detect CD56. In the double labeling of CD271 in combination with W8B2, we observed nearly $100 \%$ of the CFU-F of human, monkey, and goat in the $\mathrm{CD} 271^{+} \mathrm{W} 8 \mathrm{~B} 2^{+}$fraction, indicating that both these $\mathrm{mAb}$ recognize MSCs and will not reveal subpopulations. Double labeling of, for example, CD271 together with W4A5 in BM of goat and pig distinguished $\mathrm{CD} 271^{+} \mathrm{W} 4 \mathrm{~A} 5^{+}$and $\mathrm{CD} 271^{+}$W4A5 with colonyforming capacity. It will be interesting to select the different cell fractions and investigate their differentiative potential toward adipocytes, osteoblasts, and chondrocyte-like cells compared with plastic adherent cells, as Quirici et al. described a higher differentiative potential for the immunoselected populations [49].

We showed that flow sorting for all 7 markers could be used to enrich for MSCs, for both single and double labeling, although the purification factors that we obtained varied considerably (Tables 3 and 4). However, it was not our primary goal to get the highest purity, and therefore settings of the sorting gates were not further optimized. When MSCs are flow sorted from human $\mathrm{BM}$ after labeling with the $\mathrm{mAb}$ on which we report here, for example, W8B2, W5C4, W3C4, 39D5, or CD271, followed by in vitro expansion, they can be differentiated as effectively as MSCs cultured from nonsorted BM [41-43]. Others have shown this for Stro-1 [33] and for CD146 [50].

Our experiments, however, do show that the cross-reacting $\mathrm{mAb}$ that we identified are excellent markers for the clonogenic MSCs in primary BM of the various species that we studied, and we anticipate that they can be used to purify the CFU-F population from the BM from each of the species to a high degree and to study their differentiation potential. The optimal conditions to differentiate MSCs from each of these species are as yet not defined and require additional research.

In addition to using the cross-reacting $\mathrm{mAb}$ for sorting of the clonogenic MSCs from BM, they can also be used to characterize cultured MSCs. We showed that the CFU-F fraction in the $\mathrm{BM}$ was mostly restricted to the positive cell fraction after labeling with CD271, W8B2, W4A5, CD56, and W3C4, indicating that these markers are expressed by early progenitors. For these mAb we observed that upon further in vitro expansion the percentage of positive cells decreased. This observation is in agreement with the fact that MSCs lose their stem cell characteristics like self-renewal and differentiation capacity upon prolonged culturing [51-53]. In contrast, most of the MSCs remained positive for 58B1 and W5C4 during expansion culturing.

Culture expansion of MSCs aims to produce large numbers of cells either for functional testing in preclinical models or to use for cellular therapy in human regenerative medicine applications. The frequency of the clonogenic MSCs (CFU-F) in the initial $\mathrm{BM}$ is low, in the order of 1 per $10^{4}-10^{5} \mathrm{BM}$ cells $(0.01 \%-0.001 \%)$. To produce large numbers of MSCs there are several options: (1) start with a relatively large amount of BM and consequently a very large number of culture flasks; (2) start with a limited number of BM cells and expand the MSCs during serial passaging until sufficient numbers of cells are obtained; (3) expand the culture after prospective isolation of the MSCs from the BM. Our study shows that the last option can be done not only for human BM but also for any of the species that we studied using the mAb against CD271 in combination with W8B2, W4A5, or CD56. The first option requires a large amount of physical space in the cul- 
turing facility, and is less attractive from an economic point of view. The second option implies that the culture-initiating clonogenic MSCs (CFU-F) from the starting culture will undergo a large number of population doublings (PD) before the required large number of MSCs are obtained. Since MSCs go into senescence after on average 40 PD [51], option 2 will seriously affect their in vitro differentiation capacity [52] and obviously a reduced in vivo proliferation and differentiation capacity [53]. The third is the most attractive because it facilitates the processing of larger BM samples. It not only allows to scale down the voluminous MSCs cultures but also leads to a substantial increase in the absolute number of culture-initiating clonogenic MSCs (CFU-F) in the starting culture.

The relevance of this should not be underestimated. First, the MSC population in the initial passage will consist of a much larger spectrum of different clones that each has made less PD than the MSCs that are produced using option 2 and as a consequence may have retained a more immature MSC phenotype. The combination of the different markers that we identified will facilitate further purification of the clonogenic MSC population from BM or other sources for the different species. Further, a less immature cell population might be interesting to use when the dose is the limiting factor for therapy. For example, in the treatment of ischemic heart failure, the use of MSCs has clinical potential [54,55]. Culturing cells for a prolonged period might turn them less immature than primitive MSCs directly isolated from the source, and also harbors the risk that cells become tumorigenic or get infected.

\section{Conclusion}

This study provides an important first step in the identification of $\mathrm{mAb}$ that can be used for isolation and enrichment of MSCs from the BM or as key markers for the characterization of cultured MSCs from multiple mammalian species used in preclinical regenerative medicine research.

\section{Acknowledgments}

The authors thank J.F. Gaiser and G. Spierenburg for flow sorting, and R. Geuze, M.D. (University Medical Center Utrecht, The Netherlands), J.L. Bron, M.D., R.J. Kroeze, M.D. (VU Medical Center Amsterdam, The Netherlands), and Dr. P. Buma (Radboud University Medical Center, Nijmegen, The Netherlands) for goat BM, Dr. G. Wagemaker (Erasmus Medical Center Rotterdam, The Netherlands) for monkey BM, and Dr. W. Noort (University Medical Center Utrecht, The Netherlands) for providing BM samples from pig and sheep, and Dr. L. Theyse (University Utrecht, The Netherlands) for providing BM samples from dog. The authors also want to thank Prof. P.J. Coffer for proofreading the article.

This work was supported by a grant from the Dutch Program for Tissue Engineering (DPTE, project 6729) and by a grant from the Deutsche Forschungsgemeinschaft (project BU 516/2-1: Identification and Functional Characterization of MSC-Specific Molecules).

\section{Author Disclosure Statement}

No competing financial interests exist.

\section{References}

1. Prockop DJ. (1997). Marrow stromal cells as stem cells for nonhematopoietic tissues. Science 276:71-74.

2. Bianco P, PG Robey and PJ Simmons. (2008). Mesenchymal stem cells: revisiting history, concepts, and assays. Cell Stem Cell 10:313-319.

3. Pittenger MF, AM Mackay, SC Beck, RK Jaiswal, R Douglas, JD Mosca, MA Moorman, DW Simonetti, S Craig and DR Marshak. (1999). Multilineage potential of adult human mesenchymal stem cells. Science 284:143-147.

4. Kode JA, S Mukherjee, MV Joglekar and AA Hardikar. (2009). Mesenchymal stem cells: immunobiology and role in immunomodulation and tissue regeneration. Cytotherapy 11:377-391.

5. Dominici M, K Le Blanc, I Mueller, I Slaper-Cortenbach, F Marini, D Krause, R Deans, Keating A, DJ Prockop and Horwitz E. (2006). Minimal criteria for defining multipotent mesenchymal stromal cells. The International Society for Cellular Therapy position statement. Cytotherapy 8:315-317.

6. Murphy JM, DJ Fink, EB Hunziker and FP Barry. (2003). Stem cell therapy in a caprine model of osteoarthritis. Arthritis Rheum 48:3464-3474.

7. Kruyt MC, WJ Dhert, H Yuan, CE Wilson, CA van Blitterswijk, AJ Verbout and JD de Bruijn. (2004). Bone tissue engineering in a critical size defect compared to ectopic implantations in the goat. J Orthop Res 22:544-551.

8. Kruyt MC, WJ Dhert, FC Oner, CA van Blitterswijk, AJ Verbout and JD de Bruijn. (2007). Analysis of ectopic and orthotopic bone formation in cell-based tissue-engineered constructs in goats. Biomaterials 28:1798-1805.

9. Hoogendoorn RJ, ZF Lu, RJ Kroeze, RA Bank, PI Wuisman and MN Helder. (2008). Adipose stem cells for intervertebral disc regeneration: current status and concepts for the future. J Cell Mol Med 12:2205-2216.

10. Wang C, Z Wang, A Li, F Bai, J Lu, S Xu and D Li. (2009). Repair of segmental bone-defect of goat's tibia using a dynamic perfusion culture tissue engineering bone. J Biomed Mater Res A 92:1145-1153.

11. Nair MB, HK Varma, KV Menon, SJ Shenoy and A John. (2009). Reconstruction of goat femur segmental defects using triphasic ceramic-coated hydroxyapatite in combination with autologous cells and platelet-rich plasma. Acta Biomater 5:1742-1755.

12. Bruder SP, KH Kraus, VM Goldberg and S Kadiyala. (1998). The effect of implants loaded with autologous mesenchymal stem cells on the healing of canine segmental bone defects. J Bone Joint Surg Am 80:985-996.

13. Hiyama A, J Mochida, T Iwashina, H Omi, $\mathrm{T}$ Watanabe, $\mathrm{K}$ Serigano, F Tamura and D Sakai. (2008). Transplantation of mesenchymal stem cells in a canine disc degeneration model. J Orthop Res 26:589-600.

14. Jang BJ, YE Byeon, JH Lim, HH Ryu, WH Kim, Y Koyama, M Kikuchi, KS Kang and OK Kweon. (2008). Implantation of canine umbilical cord blood-derived mesenchymal stem cells mixed with beta-tricalcium phosphate enhances osteogenesis in bone defect model dogs. J Vet Sci 9:387-393.

15. Neupane M, CC Chang, M Kiupel and V YuzbasiyanGurkan. (2008). Isolation and characterization of canine adipose-derived mesenchymal stem cells. Tissue Eng Part A 14:1007-1015.

16. Kon E, A Muraglia, A Corsi, P Bianco, M Marcacci, I Matin, A Boyde, I Ruspantini, P Chistolini, M Rocca, R Giardino, T Cancedda and R Quarto. (2000). Autologous bone marrow stromal cells loaded onto porous hydroxyapatite ceramic 
accelerate bone repair in critical-size defects of sheep long bones. J Biomed Mater Res 49:328-337.

17. Mrugala D, C Bony, N Neves, L Caillot, S Fabre, D Moukoko, C Jorgensen and D Noël. (2008). Phenotypic and functional characterisation of ovine mesenchymal stem cells: application to a cartilage defect model. Ann Rheum Dis 67:288-295.

18. McCarty RC, S Gronthos, AC Zannettino, BK Foster and CI Xian. (2009). Characterisation and developmental potential of ovine bone marrow derived mesenchymal stem cells. J Cell Physiol 219:324-333.

19. Korda M, G Blunn, A Goodship and J Hua. (2008). Use of mesenchymal stem cells to enhance bone formation around revision hip replacements. J Orthop Res 26:880-885.

20. Sheyn D, G Pelled, Y Zilberman, F Talasazan, JM Frank, D Gazit and Z Gazit. (2008). Nonvirally engineered porcine adipose tissue-derived stem cells: use in posterior spinal fusion. Stem Cells 26:1056-1064.

21. Kumar BM, JG Yoo, SA Ock, JG Kim, HJ Song, EJ Kang, SK Cho, SL Lee, JH Cho, S Balasubramanian and GJ Rho. (2007). In vitro differentiation of mesenchymal progenitor cells derived from porcine umbilical cord blood. Mol Cells 24: 343-350.

22. Potapova IA, SV Doronin, DJ Kelly, AB Rosen, AJ Schuldt, Z Lu, PV Kochupura, RB Robinson, MR Rosen, PR Brink, GR Gaudette and IS Cohen. (2008). Enhanced recovery of mechanical function in the canine heart by seeding an extracellular matrix patch with mesenchymal stem cells committed to a cardiac lineage. Am J Physiol Heart Circ Physiol 295:2257-2263.

23. Silva GV, S Litovsky, JA Assad, AL Sousa, BJ Martin, D Vela, SC Coulter, J Lin, Ober J, WK Vaughn, RV Branco, EM Oliveira, R He, YJ Geng, JT Willerson and EC Perin. (2005). Mesenchymal stem cells differentiate into an endothelial phenotype, enhance vascular density, and improve heart function in a canine chronic ischemia model. Circulation 111:150-156.

24. Perin EC, GV Silva, JA Assad, D Vela, LM Buja, AL Sousa, S Litovsky, J Lin, WK Vaughn, S Coulter, MR Fernandes and JT Willerson. (2008). Comparison of intracoronary and transendocardial delivery of allogeneic mesenchymal cells in a canine model of acute myocardial infarction. J Mol Cell Cardiol 44:486-495.

25. Krause U, C Harter, A Seckinger, D Wolf, A Reinhard, F Bea, T Dengler, S Hardt, A Ho, HA Katus, H Kuecherer and A Hansen. (2007). Intravenous delivery of autologous mesenchymal stem cells limits infarct size and improves left ventricular function in the infarcted porcine heart. Stem Cells Dev 16:31-37.

26. Amado LC, AP Saliaris, KH Schuleri, M St. John, JS Xie, S Cattaneo, DJ Durand, T Fitton, JQ Kuang, G Stewart, S Lehrke, WW Baumgartner, BJ Martin, AW Heldman and JM Hare. (2005). Cardiac repair with intramyocardial injection of allogeneic mesenchymal stem cells after myocardial infarction. Proc Natl Acad Sci USA 102:11474-11479.

27. Hamamoto H, JH Gorman 3rd, LP Ryan, R Hinmon, TP Martens, MD Schuster, T Plappert, M Kiupel, MG St. JohnSutton, S Itescu and RC Gorman. (2009). Allogeneic mesenchymal precursor cell therapy to limit remodeling after myocardial infarction: the effect of cell dosage. Ann Thorac Surg 87:794-801.

28. Vincentelli A, F Wautot, F Juthier, O Fouquet, D Corseaux, S Marechaux, T Le Tourneau, O Fabre, S Susen, E Van Belle, F Mouquet, C Decoene, A Prat and B Jude. (2007). In vivo autologous recellularization of a tissue-engineered heart valve: are bone marrow mesenchymal stem cells the best candidates? J Thorac Cardiovasc Surg 134:424-432.

29. Isakova IA, K Baker, M DuTreil, J Dufour, D Gaupp and DG Phinney. (2007). Age- and dose-related effects on MSC engraftment levels and anatomical distribution in the central nervous systems of nonhuman primates: identification of novel MSC subpopulations that respond to guidance cues in brain. Stem Cells 25:3261-3270.

30. Hu J, QT Zhu, XL Liu, YB Xu and JK Zhu. (2007). Repair of extended peripheral nerve lesions in rhesus monkeys using acellular allogenic nerve grafts implanted with autologous mesenchymal stem cells. Exp Neurol 204:658-666.

31. Deng YB, XG Liu, ZG Liu, XL Liu, Y Liu and GQ Zhou. (2006). Implantation of BM mesenchymal stem cells into injured spinal cord elicits de novo neurogenesis and functional recovery: evidence from a study in rhesus monkeys. Cytotherapy 8:210-214.

32. Davis SF, J Hood, A Thomas and BA Bunnell. (2006). Isolation of adult rhesus neural stem and progenitor cells and differentiation into immature oligodendrocytes. Stem Cells Dev 15:191-199.

33. Gronthos S, SE Graves, S Ohta and PJ Simmons. (1994). The STRO- $1^{+}$fraction of adult human bone marrow contains the osteogenic precursors. Blood 84:4164-4173.

34. Quirici N, D Soligo, P Bossolasco, F Servida, C Lumini and GL Deliliers. (2002). Isolation of bone marrow mesenchymal stem cells by anti-nerve growth factor receptor antibodies. Exp Hematol 30:783-791.

35. Gang EJ, D Bosnakovski, CA Figueiredo, JW Visser and RC Perlingeiro. (2007). SSEA-4 identifies mesenchymal stem cells from bone marrow. Blood 109:1743-1751.

36. Sacchetti B, A Funari, S Michienzi, S di Cesare, S Piersanti, I Saggio, E Tagliafico, S Ferrari, PG Robey, M Riminucci and P Bianco. (2007). Self-renewal osteoprogenitors in bone marrow sinusoids can organize a hematopoietic microenvironment. Cell 131:324-336.

37. Deschaseaux F, F Gindraux, R Saadi, L Obert, D Chalmers and P Herve. (2003). Direct selection of human bone marrow mesenchymal stem cells using an anti-CD49a antibody reveals their CD45 med,low phenotype. Br J Haematol 122: 506-517.

38. Majumdar MS, V Banks, DP Peluso and EA Morris. (2000). Isolation, characterization, and chondrogenic potential of human bone marrow-derived multipotent stromal cells. J Cell Physiol 185:98-106.

39. Aslan H, Y Zilberman, L Kandel, M LieberGall, RJ Oskouian, D Gazit and Z Gazit. (2006). Osteogenic differentiation of noncultured immunoisolated bone marrow-derived CD105 cells. Stem Cells 24:1728-1737.

40. Martinez C, TJ Hofmann, R Marino, M Dominici and E Horwitz. (2007). Human bone marrow mesenchymal stromal cells express the neural ganglioside GD2: a novel surface marker for the identification of MSCs. Blood 109: 4245-4248.

41. Battula VL, S Treml, H Abele and HJ Bühring. (2008). Prospective isolation and characterization of mesenchymal stem cells from placenta using a frizzled-9 specific monoclonal antibody. Differentiation 76:326-336.

42. Bühring HJ, VL Battula, S Treml, B Schewe, L Kanz and W Vogel. (2007). Novel markers for the prospective isolation of human MSC. Ann NY Acad Sci 1106:262-271.

43. Battula VL, S Treml, PM Bareiss, F Gieseke, H Roelofs, P de Zwart, I Müller, B Schewe, T Skutella, WE Fibbe, L Kanz and HJ Bühring. (2009). Isolation of functionally distinct mesen- 
chymal stem cell subsets using antibodies against CD56, CD271 and mesenchymal stem cell antigen-1 (MSCA-1). Haematologica 94:173-184.

44. Prins H-J, H Rozemuller, S Vonk-Griffioen, VG Verweij, W Dhert, I Slaper-Cortenbach and AC Martens. (2009). Bone forming capacity of mesenchymal stromal cells when cultured in the presence of human platelet lysate as substitute for fetal bovine serum. Tissue Eng Part A 15:3741-3751.

45. Smits AM, P van Vliet, CH Metz, T Korfage, JP Sluijter, PA Doevendans and MJ Goumans. (2009). Human cardiomyocyte progenitor cells differentiate into functional mature cardiomyocytes: an in vitro model for studying human cardiac physiology and pathophysiology. Nat Protoc 4:232-243.

46. Vogel W, F Grünebach, CA Messam, L Kanz, W Brugger and HJ Bühring. (2003). Heterogeneity among human bone marrow-derived mesenchymal stem cells and neural progenitor cells. Haematologica 88:126-133.

47. Logan CY and R Nusse. (2004). The Wnt signaling pathway in development and disease. Annu Rev Cell Dev 20:781-810.

48. Sobiesiak M, K Sivasubramaniyan, C Hermann, C Tan, M Orgel, S Treml, F Cerabona, P Dezwart, U Ochs, CA Müller, CE Gargett, H Kalbacher and HJ Bühring. (2009). The mesenchymal stem cell antigen MSCA-1 is identical to tissue nonspecific alkaline phosphatase. Stem Cells Dev 19:669-677.

49. Quirici N, C Scavullo, L de Girolamo, S Lopa, E Arrigoni, G Lambertenghi Deliliers and AT Brini. (2009). Anti-L-NGFR and -CD34 monoclonal antibodies identify multipotent mesenchymal stem cells in human adipose tissue. Stem Cells Dev 19:915-925.

50. Schwab KE and CE Gargett. (2007). Co-expression of two perivascular cell markers isolates mesenchymal stem-like cells from human endometrium. Hum Reprod 22:2903-2911.

51. Bruder SP, N Jaiswal and SE Haynesworth. (1997). Growth kinetics, self-renewal, and the osteogenic potential of purified human mesenchymal stem cells during extensive sub- cultivation and following cryopreservation. J Cell Biochem 64:278-294.

52. Siddappa R, R Licht, C van Blitterswijk and J de Boer. (2007). Donor variation and loss of multipotency during in vitro expansion of human mesenchymal stem cells for bone tissue engineering. J Orthop Res 25:1029-1041.

53. Agata H, I Asahina, N Watanabe, Y Ishii, N Kubo, S Ohshima, M Yamazaki, A Tojo and H Kagami. (2009). Characteristic change and loss of in vivo osteogenic abilities of human bone marrow stromal cells during passage. Tissue Eng Part A 16:663-673.

54. Shake JG, PJ Gruber, WA Baumgartner, G Senechal, J Meyers, JM Redmond, MF Pittenger and BJ Martin. (2002). Mesenchymal stem cell implantation in a swine myocardial infarct model: engraftment and functional effects. Ann Thorac Surg 73:1919-1925.

55. Yau TM, S Tomita, RD Weisel, ZQ Jia, LC Tumiati, DA Mickle and RK Li. (2003). Beneficial effect of autologous cell transplantation on infarcted heart function: comparison between bone marrow stromal cells and heart cells. Ann Thorac Surg 75:169-176.

Address correspondence to: Dr. Anton C. Martens Department of Immunology, HP: KC02.085.2 University Medical Center Utrecht

P.O. Box 85090 3584 EA Utrecht The Netherlands

E-mail: a.martens@umcutrecht.nl

Received for publication December 16, 2009

Accepted after revision April 3, 2010

Prepublished on Liebert Instant Online April 5, 2010 
